\title{
LA INCOHERENCIA DEL REALISMO INTERNO
}

GuLlermo HurTado

INstrTuto de INvestigaciones Filosóficas

UNAM

El realismo interno es una doctrina que permite lecturas muy distintas. En parte, esto se debe a que ha sido presentada, primordialmente, como una tesis negativa. El realismo interno se define por su rechazo al realismo metafísico, que, según Putnam, consiste en la doctrina que defiende las siguientes tres tesis: 1) el mundo consiste en una totalidad fija de objetos independientes de la mente, 2) hay exactamente una descripción verdadera y completa del mundo, $y$, por último, 3) la verdad consiste en algún tipo de correspondencia. ${ }^{1}$ Putnam sostiene que no podemos defender ninguna de estas tres tesis sin defender las otras dos, es decir, que se trata de un paquete integral. Pero creo que podemos defender versiones más débiles de 1) y 2) y seguir manteniendo 3); o defender 1) y rechazar 3), como es el caso de aquellos que creen en la existencia de un mundo ya hecho, pero no aceptan la teoría de la correspondencia de la verdad. Por esta razón, a pesar de considerarme un realista no interno, no me siento obligado a defender el paquete entero. El realismo metafísico, me parece, no es la mejor manera - ni la más sofisticada- de defender la intuición central del Realismo con mayúsculas, que es, a fin de cuentas, el blanco de los argumentos de Putnam. Ahora bien, es evidente que una vez rechazado el realismo metafísico, podemos escoger entre un amplio abanico de posibilidades teóricas. Por ejemplo, la negación de 1) nos permite adoptar cualquiera de las siguientes tres alternativas: $l^{\prime}$ ) el mundo consiste en una totalidad variable de objetos independientes de la mente, $1^{\prime \prime}$ ) el mundo consiste

1 El realismo interno ha sido defendido por Hilary Pumam en sus libros Reason, Truth and History, Cambridge U.P., 1981; Realism and Reason, Cambridge U.P., 1983; The Many Faces of Realism, Open Court, La Salle, 1987; Realism with a Human Face, Cambridge U.P., 1990. Debo aclarar que la postura actual de Putnam puede ser distinta a la que aquí se critica, ya que en un reciente simposio organizado por el Instituto de Investigaciones Filosóficas de la Universidad Autónoma de México (Taxco, septiembre, 1992) Putnam negó que la interpretación del realismo interno aquí sugerida sea la más adecuada. Sin embargo, ya que mi interpretación está fundamentada en afirmaciones hechas por el propio Putnam en las obras arriba citadas y que me consta que hay quienes, inspirándose en Putnam, defienden explícitamente doctrinas muy parecidas a lo que yo critico, me parece que no es del todo gratuito marcar mi punto. 
en una totalidad indeterminada de objetos independientes de la mente, y, por último, $I^{\prime \prime \prime}$ ) el mundo carece de objetos independientes de la mente. Si bien habría pocos realistas que tendrían inconvenientes en aceptar $\mathrm{l}^{\prime}$ ), la tesis $\mathrm{I}^{\prime \prime \prime}$ ) nos lleva a los aciagos dominios del idealismo. Pero si bien Putnam ha sido suficientemente claro con respecto a su rechazo total del realismo metafísico, ha sido desesperadamente poco claro con respecto a su caracterización positiva del realismo interno. Vamos a ver más adelante algunas de las tensiones que existen entre distintas afirmaciones de Putnam con respecto a la naturaleza de la realidad independiente de la mente. Pero mi propósito en este ensayo es ofrecer una crítica a la interpretación que me parece más natural y más común del realismo interno visto como una doctrina acerca de la naturaleza última de la realidad. La conclusión a la que voy a llegar es que el realismo interno es, o bien informulable, o bien inconsistente. Soy consciente de que hay otras maneras de interpretar el realismo interno que no caen en los problemas aquí señalados; pero me parece que estas lecturas -cuando no son demasiado descabelladas - son, a fin de cuentas, equivalentes a posturas relativistas más bien triviales que no minan la intuición fundamental del realismo, a saber, que la existencia de la realidad, o de al menos buena parte de ella, no depende de la mente o del lenguaje.

La versión del realismo interno que considero sostiene que el mundo en que vivimos (el mundo de las sillas, los protones, las sinfonías, etc.) no podría existir sin la actividad discriminatoria y conceptualizadora de la mente; sin embargo, mantiene también que dicho mundo no es una creación ex nibilo de la mente. El realismo interno afirma que si no hubiera mentes no habría sillas, protones, sinfonías, etc., pero habría, de todos modos, alguna realidad (muy distinta del mundo en el que vivimos); y a veces parece sostener algo más fuerte: que no podría haber mentes (y por tanto sillas, protones y sinfonías) a menos que previamente existiera una realidad independiente de la mente. Tal y como yo entiendo lo anterior, el realismo interno sostiene que todas las determinaciones ontológicas son provistas por los esquemas conceptuales y que, por tanto, la realidad independiente de la mente es absolutamente indeterminada. Una manera de entender la tesis de que la realidad independiente de la mente es absolutamente indeterminada, es verla como la propuesta de que en dicha realidad haya objetos pero que sea totalmente indeterminado qué propiedades positivas o negativas, relacionales o monádicas, sean poseídas por dichos objetos y que, por tanto, no sea ni verdadero ni falso afirmar que un objeto tenga alguna propiedad positiva o negativa, relacional o monádica. Esta versión del realismo interno se acercaría a un noumenalismo kantiano. Sin embargo, cuando uno lee a Putnam, advierte que lo que él tiene en mente es algo todavía más fuerte. Voy a sostener que el realismo interno, tomado al pie de la letra, implica la tesis de que en la realidad independiente de la mente no bay ni objetos, ni propiedades, ni hechos. 
Putnam mismo se ha encargado de aclarar que su concepción de la realidad independiente de la mente difiere del mundo noumenal kantiano. Por una parte Putnam considera inaceptable la existencia de una Ding an sich sin ninguna propiedad en sí misma pero que pueda tener todas las propiedades que uno quiera atribuirle en un modelo. Esto no significa que Putnam crea que las cosas en sí tengan propiedades independientemente de los modelos, sino que, simplemente, ya que no hay propiedades intrínsecas - es decir, propiedades que las cosas tengan en sí mismas sin la intervención de la menteno hay tales cosas en sí. Pero, por otra parte, también nos diría que el mundo noumenal kantiano, visto de cerca, no es tan carente de determinaciones como debería serlo. Por dar un ejemplo, hay razones para suponer que Kant creía que hay pluralidad en el mundo noumenal. Pero un mundo en donde hay pluralidad no puede ser absolutamente indeterminado, ya que en dicho mundo habría diversidad intrínseca - sería determinado que algo no sea idéntico a algo más- y por tanto habría al menos una propiedad poseída por todos y cada uno de los noumena. La proposición de que para todo $x$ hay algún $y$ tal que $x$ es distinto de $y$ sería una proposición verdadera en el mundo noumenal. Pero no cabe duda de que esto sería señalado por el realista interno como uno más de los problemas infranqueables del noumenalismo. El realista interno diría que él no está comprometido ni con una pluralidad de cosas en sí, ni mucho menos con diferencias cualitativas entre las cosas en sí, porque, a fin de cuentas, no hay tales cosas en sí.

Sin embargo, hay ocasiones en las que parecería que Putnam toma el camino inverso y acepta la existencia de algún tipo de objetos independientes de la mente. Es decir, da la impresión de que lo único que Putnam niega es que podamos hablar de objetos y propiedades sin mencionar un esquema conceptual; pero no que la realidad independiente de la mente tenga cierto tipo de determinaciones que de algún modo influyan para que sólo algunos esquemas conceptuales sean exitosos como una manera de entender la realidad. Putnam repite una y otra vez que los objetos no son sólo productos de nuestra invención conceptual, sino que también son descubiertos. La mente y el mundo, nos dice, son una creación conjunta de la mente y el mundo. Pero Putnam nunca nos explica de una manera satisfactoria qué quiere decir con esta frase conciliatoria; es decir, no explica cómo podemos descubrir y producir el mundo al mismo tiempo. Putnam nunca nos explica de qué manera la realidad independiente de la mente puede determinar nuestra elección de esquema conceptual si es que no hay ni objetos, ni propiedades en dicha realidad; o, a la inversa, de qué manera el esquema conceptual produce los objetos y las propiedades si es que, en un principio, ese mismo esquema conceptual fue creado en virtud de la existencia de dichos objetos y dichas propiedades. Por ejemplo, Putnam ha dicho en Reason, Truth and History (p. 53) que él 
no niega que haya cierto tipo de objetos autoidentificables, es decir, objetos que pertenezcan por sí mismos a una clase de objetos del mismo tipo; sin embargo, inmediatamente después, niega que esos objetos sean independientes de la mente. Es decir, niega que puedan existir sin haber sido clasificados por nosotros como pertenecientes a dicho tipo. El problema del realismo metafísico, añade Putnam, es querer tener objetos que sean autoidentificables y, al mismo tirmpo, independientes de la mente. Sin embargo, Putnam afirma que el hecho de que sean autoidentificables es lo que nos permite construir la versión del mundo que tenemos y en la que incluimos a dichos objetos. Pero esto último parece contradecir la afirmación de que los objetos autoidentificables existen hasta que son enmarcados por nuestro esquema conceptual. Si el hecho de que los objetos caigan de una manera intrínseca bajo ciertas etiquetas es lo que determina que tengamos la versión del mundo que tenemos, entonces parece que esos mismos objetos autoidentificables tenían que existir antes de que existiera dicha versión del mundo. ${ }^{2}$

El realismo interno, por tanto, debe dar una explicación plausible de cómo es posible que el mundo esté constituido conjuntamente por la mente y por la realidad independiente de la mente. De otra manera, es un misterio el que las mentes hayan podido surgir de una realidad absolutamente carente de determinaciones y el que la realidad independiente de la mente cause el elemento objetivo de la experiencia. Pero estos problemas no pueden ser solucionados por el realismo interno sin incurrir en algún tipo de contradicción o, al menos, en posturas dificilmente compatibles con el sentido común y las ciencias. ${ }^{3}$ Por ejemplo, nadie dudaría que para dar una explicación naturalista de la génesis del pensamiento y del lenguaje debemos asumir que el mundo existía antes de que hubiera mentes. Pero el realismo interno implica que antes de que hubiera mentes no podría haber existido el mundo. Por lo que parece que debemos rechazar, ya sea la explicación propuesta, o el realismo interno. Un realista interno podría intentar evitar esta conclusión afirmando que uno puede hablar del mundo antes de que hubiera mentes porque las mentes existen hoy en día. En otras palabras, que nuestras mentes no sólo constituyen el presente

2 Valga señalar que en la reunión de Taxco, Putnam afirmó que lo que él entiende por un objeto intrínseco no es un objeto que podría existir sin la mente, sino un objeto con un conjunto fijo de propiedades. Si la postura del realismo interno al rechazar los objetos intrínsecos se limita a la tesis de que algunas propiedades de los objetos varían de acuerdo con su relación con los sujetos que piensan acerca de ellos, yo me declararía un realista interno (y sinceramente no veo quién no lo haría). No encuentro ningún problema con esta postura siempre y cuando se sostenga que no todas las propiedades de los objetos dependen de su relación con sujetos epistémicos. Ahora bien, si lo que quiere decir Putnam es que todas las propiedades de los objetos dependen de los sujetos epistémicos con los que se relacionan entonces me pronunciaría en contra de esta posibilidad.

3 Esto ha sido mostrado claramente por Adolfo García de la Sierna en su ensayo, "La dialéctica del realismo interno" (incluido en este volumen). 
del mundo, sino todo su pasado, incluso aquel periodo de su historia cuando aún no había mentes. ${ }^{4}$ Pero esta respuesta, a pesar de ser tan sugerente, no hace sino producir más problemas que los que aparentemente soluciona.

Sin embargo, un realista interno puede sostener que no está obligado a explicar nada que rompa con sus propias reglas acerca de lo que puede ser dicho. Los límites del discurso - nos diría - son los límites del mundo que nosotros constituimos. Y si algo no puede explicarse - añadiría - entonces no merecía ser explicado en primer lugar; en otras palabras, no era un problema genuino. Sin embargo, el realista interno debe decirnos algo acerca de la realidad independiente de la mente si quiere distinguirla del mundo constituido por nuestro esquema conceptual. Tal caracterización de la realidad independiente de la mente podría ser puramente negativa. Pero incluso las caracterizaciones negativas de $x$ son descripciones de $x$. Decir que algo carece de tales y cuales propiedades es decir algo acerca de dicho objeto. Por tanto, parecería que el realista interno debe seguir el famoso dictum wittgensteiniano y guardar silencio acerca de aquello de lo que no puede hablar. Sin embargo, esta regla es muy difícil de seguir por todos aquellos que se imponen a sí mismos restricciones discursivas. Un monje cartujo puede hacer voto de silencio sin dar mayores explicaciones, pero el silencio de un filósofo, cuando es una postura filosófica y no un mero capricho o un defecto de las cuerdas vocales, debe estar precedido de algún tipo de pronunciamiento acerca de por qué es guardado. Pero he aquí el problema, ya que si lo que se propone es un límite al discurso posible, entonces no podemos marcar ese límite desde el propio lenguaje sin traspasarlo. Como Russell dijera alguna vez, es imposible dejar de mencionar algo diciendo que no lo vamos a mencionar. Pero el realista interno no puede permanecer absolutamente callado acerca de la realidad independiente de la mente. A fin de formular su posición $-\mathrm{y}$ distinguirla del idealismo subjetivo- debe decir, al menos, que hay tal realidad independiente de la mente. Y esto no es sólo hacer ruiditos, sino que es hacer una afirmación de tremendas proporciones, a saber, que el ser no es lo mismo que el pensar. A estas alturas, el realista interno puede verse tentado a echar mano de la noción wittgensteiniana de mostrar (zeigen). De esta forma, pretendería mostrarnos la existencia de la realidad independiente de la mente sin decirnos nada acerca de ella. Pero me parece que la noción de mostrar involucra algún tipo de trampa. Es como si en un juego de salón le prohibiéramos a uno de los participantes que expresara lo que piensa y que, sin embargo, en vez de decírnoslo con palabras, nos lo hiciera saber por medio de gestos. Lo que importa en realidad no son los límites del lenguaje, sino los límites de la expresión y de la

4 Con respecto a este punto véase el ensayo de Nicholas Wolterstorff, "Are Concepts-users World Makers?", en Philosophical Perspectives, 1, ed. de James Tomberlin, Ridgview Publishing Company, Arascadero, 1987. 
comprensión. En lo que resta de este ensayo voy a atacar el realismo interno desde otro frente. Voy a considerar la pregunta de si su noción de la realidad independiente de la mente tiene sentido y es defendible.

A primera vista la noción de una realidad absolutamente indeterminada parece no ser contradictoria. Pero me parece que el realista interno se enfrenta a la siguiente pregunta: si no hay objetos, no hay propiedades y no hay hechos en la realidad independiente de la mente, ¿qué la distingue de la Nada? El realista interno, ya sabemos, puede optar por no responder esta pregunta; puede, incluso, fingir no entenderla. Pero si se queda callado, entonces estaremos en nuestro pleno derecho de afirmar que no entendemos lo que distingue su posición de la de un idealista (excepto que él sí contesta nuestras preguntas). Quizá la idea que desea defender un realista interno es que la realidad independiente de la mente es el ser puro, es decir, ser sin determinaciones. Pero, como diría Hegel, este ser puro es la abstracción pura, es la ausencia absoluta de determinaciones y, por consiguiente, no puede distinguirse del no ser. Por lo que podemos decir que si no hay manera en la que se pueda distinguir la realidad independiente de la mente de la nada, el realismo interno se derrumba en tanto que propuesta metafisica.

La anterior consiste, virtualmente, en una refutación del realismo interno, pero conviene que examinemos si el realista interno tiene alguna vía de escape. Volvamos a plantear nuestra pregunta de la siguiente manera: isi no hay objetos, ni propiedades, ni hechos en la realidad independiente de la mente, entonces qué hay? Una respuesta que intente evitar la refutación arriba propuesta, es decir que lo que hay es la realidad independiente de la mente y que esta realidad tiene ciertas características, por ejemplo, carecer de objetos, propiedades y hechos; pero, a esto se añadiría que decir que la realidad independiente de la mente existe y tiene ciertas características no es lo mismo que tomarla como un objeto y atribuirle ciertas propiedades. Podría incluso decirse que el hecho de que la realidad independiente de la mente sea el único objeto que hay, no puede ser un hecho de la realidad independiente de la mente y que, por tanto, puede seguirse manteniendo que la realidad independiente de la mente no tiene ni objetos, ni propiedades, ni hechos. Pero ésta sólo puede ser una salida si la realidad de orden superior que incluye a la realidad independiente de la mente como uno de sus objetos no es, a su vez, independiente de la mente. Ahora bien, me parece, que el hecho de que un mundo tenga tales y cuales características es un hecho que puede formar parte, sin contradicción alguna, del inventario de hechos de tal mundo. Por ejemplo, el hecho de que en nuestro mundo los entes estén organizados en ciertas categorías es un hecho de este mundo, no de otro. Lo que quizá sea más debatible, debido a bien conocidas paradojas, es si un mundo puede ser miembro del conjunto de objetos de dicho mundo. Sin embargo, como vere- 
mos ahora mismo, lo importante es que todos los hechos acerca de un mundo pertenezcan a ese mundo.

Un mundo sin particulares es perfectamente posible. Podemos imaginar que cada cosa del universo sea eliminada una por una hasta acabar con todas. En un sentido del término éste sería un mundo vacío. Pero no sería un mundo en donde nada fuera el caso. Si bien un mundo sin particulares es posible, un mundo sin hechos es imposible. ${ }^{5}$ Por ejemplo, si no hay cosas sólidas, la proposición general negativa de que no hay ninguna $x$ tal que $x$ es sólida será verdadera. Un mundo en donde no haya particulares será un mundo donde, de todas maneras, habrá hechos negativos de muchos tipos, $y$, por tanto, no será un mundo totalmente vacío. Pero el que haya hechos en un mundo - y éste es el punto central que deseo defender - basta para que dicho mundo tenga determinaciones intrínsecas. Lo que a fin de cuentas distingue a un mundo posible de otro son sus hechos, no sus objetos. En otras palabras, son los hechos y no los objetos los que determinan la identidad de un mundo posible. Pero para Putnam no tiene sentido hablar de hechos independientes de un esquema conceptual. Por ejemplo, en The Many Faces of Realism (p. 36), nos llega a decir que hablar de hechos independientes del lenguaje es hablar de nada. Para Putnam el significado de la palabra "hecho" - así como el de las palabras "objeto" y "existencia" - no está determinado por nada de la realidad misma y, por tanto, según él, no hay hechos intrínsecos: sino tantos hechos como sean postulados por esquemas conceptuales. Sin embargo, en el mundo independiente de la mente descrito por el realismo interno hay varios hechos intrínsecos, es decir, hechos que se dan sin que haya mentes que los consideren. Por ejemplo, si la proposición que expresa que no hay nada en el mundo independiente de la mente y que por tanto no hay nada que tenga una propiedad es una proposición verdadera, entonces su verdad no dependerá de ningún esquema conceptual, sino de cómo es ese mundo. El que no haya nada será una característica intrínseca de un mundo que, por definición, es tal y como es independientemente de cualquier mente. Pero la que no puede ser verdadera es la proposición de que no haya determinaciones, es decir, que no haya hechos en ese mundo, ya que no hay un mundo sin hechos. Por lo tanto, debe ser posible hacer una descripción verdadera de cualquier mundo, por más poco que haya en él o por más confuso que sea. La idea de

5 Un filósofo de tendencias aristotélicas rechazaría esta afirmación sobre la base de la tesis de que sin individuos no puede haber nada más, ni siquiera hechos y por tanto verdades. No es éste el lugar para responder con amplitud a esta posible objeción: sin embargo, valga recalcar que mi diferencia con los aristotélicos se basa en mi creencia de que, de la misma manera en la que la noción de verdad y no la de referencia es la noción fundamental en la semántica, son los hechos y no la sustancia la categoría fundamental en la ontología. 
una realidad indescriptible no tiene sentido. La realidad independiente de la mente -cualquier realidad, para acabar pronto- debe estar determinada en algún grado. ${ }^{6}$ El realismo interno debe ofrecer una descripción de la realidad independiente de la mente y esto equivale a contradecir su propia postura, ya que describir algo es decir que algo es el caso, es indicar sus determinaciones.

6 No quisiera defender la postura de que la realidad es absolutamente determinada ya que me parece que hay muchos objetos, propiedades y clases que son intrínsecamente vagos y que esto es un hecho que debe ser aceptado por cualquier metafísica viable. ( $Y$ es por esta razón que no me siento obligado en lo más mínimo a defender los puntos 1) y 2) del realismo metafísico). 